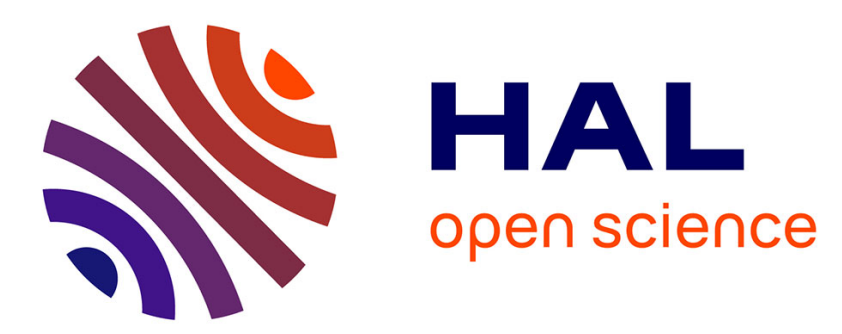

\title{
Situating Play Cultures. A survey of videogame players and practices in France
}

\author{
Samuel Rufat, Samuel Coavoux, Hovig ter Minassian
}

\section{To cite this version:}

Samuel Rufat, Samuel Coavoux, Hovig ter Minassian. Situating Play Cultures. A survey of videogame players and practices in France. Dawn Stobbart; Monica Evans. Engaging with Videogames: Play, Theory and Practice, Inter-Disciplinary Press, pp.37-51, 2014. halshs-01516211

\section{HAL Id: halshs-01516211 https://shs.hal.science/halshs-01516211}

Submitted on 28 Apr 2017

HAL is a multi-disciplinary open access archive for the deposit and dissemination of scientific research documents, whether they are published or not. The documents may come from teaching and research institutions in France or abroad, or from public or private research centers.
L'archive ouverte pluridisciplinaire HAL, est destinée au dépôt et à la diffusion de documents scientifiques de niveau recherche, publiés ou non, émanant des établissements d'enseignement et de recherche français ou étrangers, des laboratoires publics ou privés. 


\title{
Situating Play Cultures. A survey of videogame players and practices in France
}

\author{
Rufat Samuel (University of Cergy-Pontoise, Paris, France), \\ Coavoux Samuel (Ecole Normale Supérieure de Lyon, France), \\ Ter Minassian Hovig(University of Tours, France)
}

\begin{abstract}
The study of gamers and their actual practices still remains marginalized in the Game Studies academic literature. At an international level, studies and surveys have tended to spotlight the most spectacular and committed practices. As a result, large segments of gaming practices have long been neglected, introducing strong biases at the expense of less fashionable but far more standard, prevalent and everyday practices. Consequently, we advocate refocusing videogame studies on the players and moving from the fetishism of online gaming and spectacular play to the inclusion of all types of videogames and all forms of commitment and practices, without a priori expectations, in order to collect the full spectrum of practices and audiences. With this perspective, this paper explores the preliminary results of a quantitative survey conducted in 2012, which is representative of the French population over 11 years of age $(n=2,542)$. The results highlight the diversity of playing practices in space and time, as well as the divergence between social practices and their articulation to "play cultures". Similarly, the results allow us qualifying the feminization of the public, challenging the image of executives playing at work or clarifying the differences between rural and urban practices when it comes to videogames.
\end{abstract}

Key Words: Videogames, gamers, play cultures, play careers, lived space, social practices, environment, audiences, survey, France.

$* * * * *$

Videogames have become a major cultural object. However, the study of gamers and their actual practices still remains marginalized in the Game Studies academic literature. ${ }^{1}$ Existing quantitative studies are mainly carried out for the industry in order to legitimize the practice, hence they focus on the feminization of players or the constant increase in their average age (often over 35 years of age). However, these numbers do not make much sense to describe a practice to the bursting public and the boundless different levels of investment in this practice.

Thus, the lack of knowledge of videogame players limits the consolidation of the research on videogames in France. This makes it is quite difficult to answer three basic questions for both academia and the industry: who is playing 
videogames in France? How are they playing? And in what social or spatial context or environment are they playing?

In addition, videogame studies have long remained focused mostly on MMO gamers and online gaming. At an international level, studies and surveys have tended to spotlight the most spectacular and committed practices. As a result, large segments of gaming practices have long been neglected, introducing strong biases at the expense of less fashionable but far more standard, prevalent and everyday practices. Consequently, we advocate refocusing videogame studies on the players and moving from the fetishism of online gaming and spectacular play to the inclusion of all types of videogames and all forms of commitment and practices, without a priori expectations.

With this perspective, this paper will explore the preliminary results of a quantitative survey conducted in 2012, which is representative of the French population over 11 years of age $(n=2,542)$. This survey was designed as part of the LUDESPACE ${ }^{2}$ research project.

\section{The challenges of refocusing on the players}

This focus on players seeks to transcend content analysis because are the same players who at the end, make the game as well. We know that people play differently in Seoul than in Paris. ${ }^{3}$ But on a local scale, what are the demographic, social and environmental drivers of videogame practices? Videogames seem to have spread to all sections of society, but differences exist in the specific modalities of playing, principally due to the diversification of videogames' audiences (occasional vs. intensive play, solo vs. multiplayer, online vs. offline). As a result, it is important to describe how playing practices fit into gamers' lives, "play cultures" and in their "lived space" 5 " and to model their "play careers" in order to appreciate the relation between gamers' choices, their environment, and the emergence of scattered videogame practices and cultures. This requires us to explore the significant role of family socialization and to reveal the links of those practices with other cultural consumption practices but also with the places of play and the everyday lived space.

The existing data on videogame practices face three main issues. Firstly, the surveys and academic studies carried out often relate only to players 15 years of age and older, even though we know that videogames are largely present among the younger population. More qualitative works attempted to describe and explain videogame practices ${ }^{7}$, but they are either older analyses ${ }^{8}$, exclusively qualitative works ${ }^{9}$, or exclusively focused on specific genres such as MMORPG. ${ }^{10}$ In addition, a whole range of videogame' products and practices are "invisible". Most studies do not include free Internet games or default games integrated into a machine (for example card games provided with the Windows operating system). Finally, videogame practices are typically self-reported. This introduces a bias by not including people playing only occasionally, rarely, or to games that are not usually considered videogames. For example, the last "Pratiques culturelles des français" 
survey, carried out every ten years by the French Ministry of Culture, asks: "Over the last 12 months, did you play videogames?" This is a broad question, so people failing to consider their daily practice of the Solitary as playing videogames simply elude it. Thus, one of the main issues with reporting on videogame practices is that many people may not think about themselves as gamers or consider their actions as playing videogames. For all these reasons, it is of paramount importance not to base the study on an a priori definitions. In the tradition of Johan Huizinga ${ }^{12}$ and Roger Caillois' anthropology of games ${ }^{13}$, the essentialist perspective defines playing and games by a limited set of features. However, this approach presupposes the existence of game invariance allowing to decide whether or not a cultural product is a game (i.e. is an educational software a videogame?) and to normalize the practice of videogame (i.e. so many hours spent in front of a screen, such corpus of software, etc). Nevertheless, these kind of a priori expectations are the ones that have been biasing studies and obstructing the reconstruction of the full spectrum of videogame players and practices. Consequently, refocusing studies on the players requires a survey collecting the data on the actual practices, asking about all the games that the respondent plays, not only videogames, and challenging the existing categories.

\section{Design of the survey}

The survey was conducted by phone on a 2,542 person sample representative of the French population 11 years of age and over, in June 2012.

The heart of the questionnaire consists of questions about the kinds of games played. To facilitate the collection of data about practices, the survey begins with questions on cultural and sport activities in general. Then it collects data on household equipment such as TVs, consoles, phones and computers. And only then does it address games on computers, phones and consoles: Over the past 12 months, have you played at least once, either on a phone, a touch pad, a computer or a console to games installed by default - for example Minesweeper or Solitairy? The survey then breaks down the possible videogame genres, trying to avoid the commercial classifications. It begins with the genres that are more difficult to recognize as such: default games, adaptations of card games, adaptations of word and number games. 19 categories were selected, offering examples each time, starting from the games that are less often discussed in the literature and moving eventually to the most studied games (which match to the most committed practices). 


\section{Number of responses by game genres}

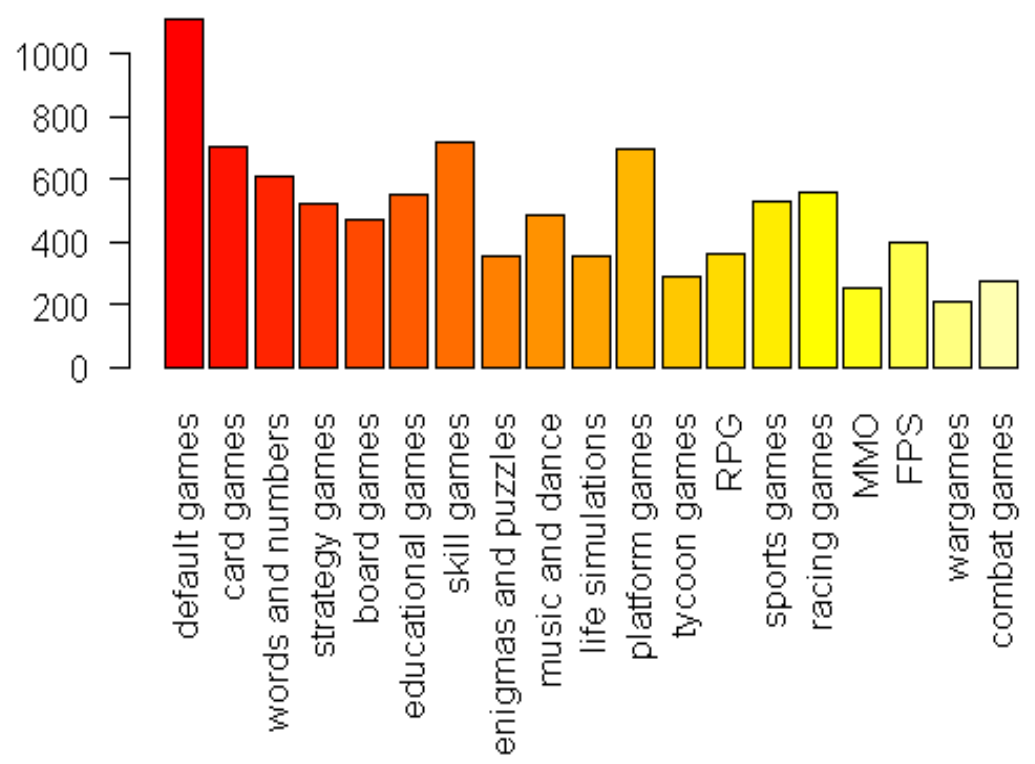

Image 1: Number of responses to the survey by game genres.

Those who reported having played at least one of these kinds of games in the last 12 months were considered players $(\mathrm{n}=1,697)$. Those who reported having played any of these games, but not during the last 12 months were considered former players $(n=276)$. Finally, other people in the sample were considered nonplayers $(n=569)$. Data on the context and the game environment was collected by asking players about their playing frequency, locations, media and playing partners. These questions were supplemented for the entire sample by demographic and background variables.

\section{Two-thirds of the French population plays videogames}

This study shows that in 2012 videogame practices now include the whole of society: both men and women, college students and retirees, blue collar workers and executives, urban and rural dwellers. Almost 6 in 10 adults reported having played (at least once) in 2012 a videogame over the last 12 months. This is an opportunity to confirm certain trends: men are slightly more likely to play than women. But also to challenge some old beliefs: in contrast to academic publications which are focused on online games and the latest hits, the most played games in France are Solitairy and Freecell, whereas MMOs are a minor genre. ${ }^{14}$ 


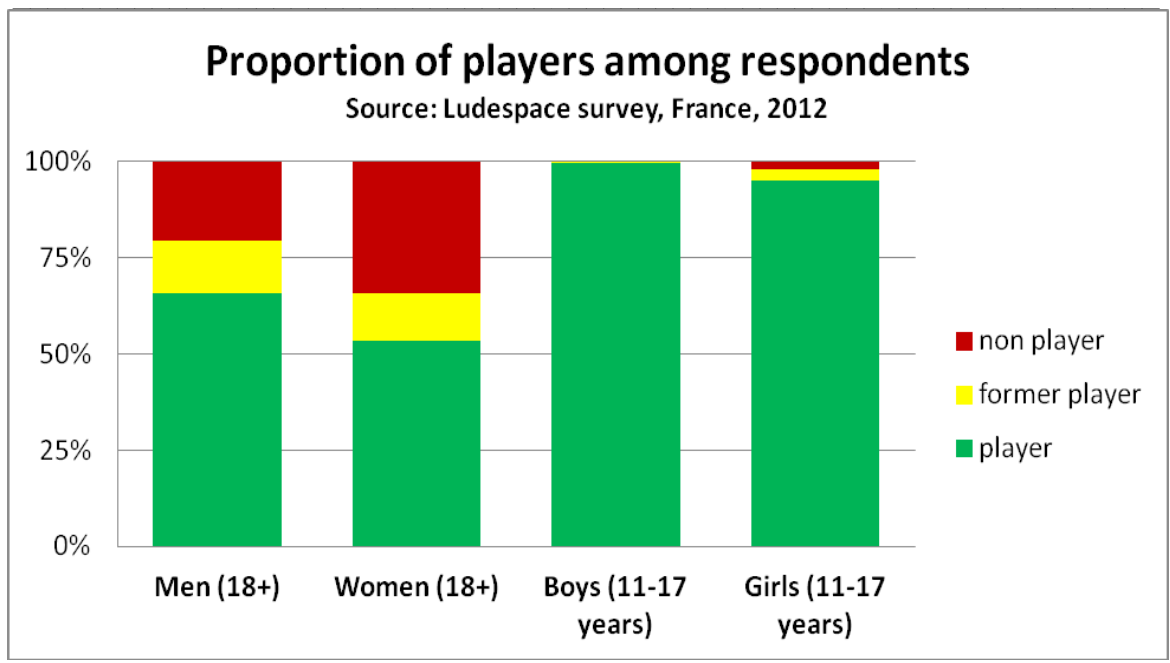

Image 2: Proportion of players among respondents.

But this generalization may seem misleading: the majority of players play videogames only occasionally and real fans are less appointed. A little more than 1 in 10 adults play almost every day. This observation is not far from that of the cinema: many people go to the movies, but few are avid moviegoers. And as for other hobbies, men and women do not maintain the same ratio as for video gaming.

\section{The gamer is a teen just like any other}

In terms of videogames, age continues to be the main element of differentiation. While almost all younger people are players, including girls, the proportion is less overwhelming in older generations and decreases with age.

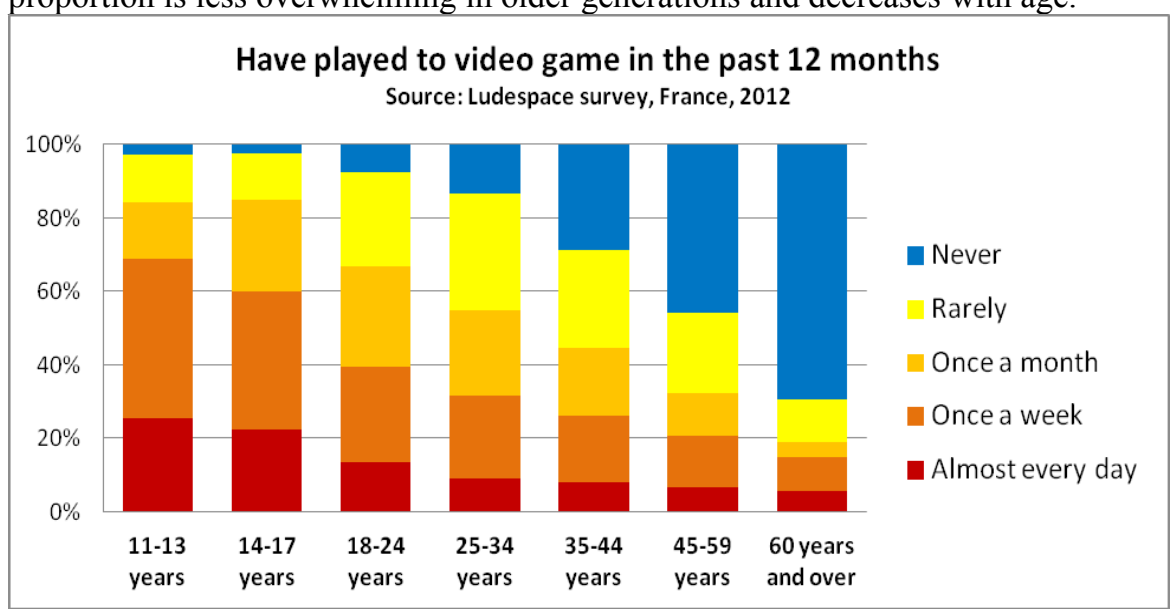

Image 3: Differentiation of practices according to the age. 
Players ages 11 to 17 years olds play everything on any device and everywhere. Among them, boys are the more involved: at least 8 out of 10 boys play every week, compared to less than 5 out of 10 girls. In addition, they generally display a more eclectic practice.

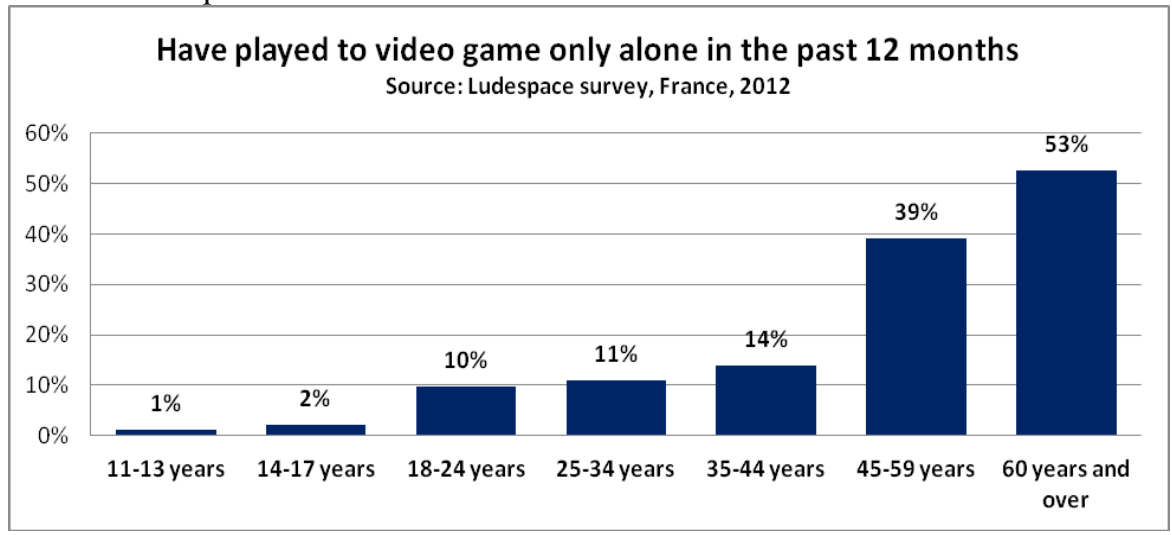

Image 4: Proportion of gamers playing only alone, by age categories.

Certain genres of videogames are actually gendered: while girls play more dance, music and life simulation games, boys prefer skill games, platform games and shooting games. Six out of 10 boys are playing FPS, compared to only 1 out of 10 girls. Moreover, the younger the player are, the wider variety of game devices they use. And for younger players, the practice of video gaming is an important agent of socialization. Those who never played (or almost never played) with other players constitute a tiny minority of younger people. On the other hand, players who only play alone represent more than half of the retired players. These differences show differentiation in practices and audiences depending largely on age and gender.

\section{Tell me what you play...}

The practice of videogames has spread to all sections of society, but differences are emerging in the specific modalities of playing, principally due to the diversification of videogame audiences. These differences reinforce the scattering of videogame practices (occasional vs. intensive play, solo vs. multiplayer, online vs. offline). Among players, more than four out of 10 blue collar workers play racing games, and more than 3 out of 10 play FPS, while less than 3 out of 10 and less than 2 out of 10 players from the intermediate professions play these games respectively. Meanwhile, skill games (Tetris, Angry Birds, etc) are more sought out by highly educated players (more than 4 in 10 among graduates of higher education, compared to less than 2 in 10 people among non-graduates). 


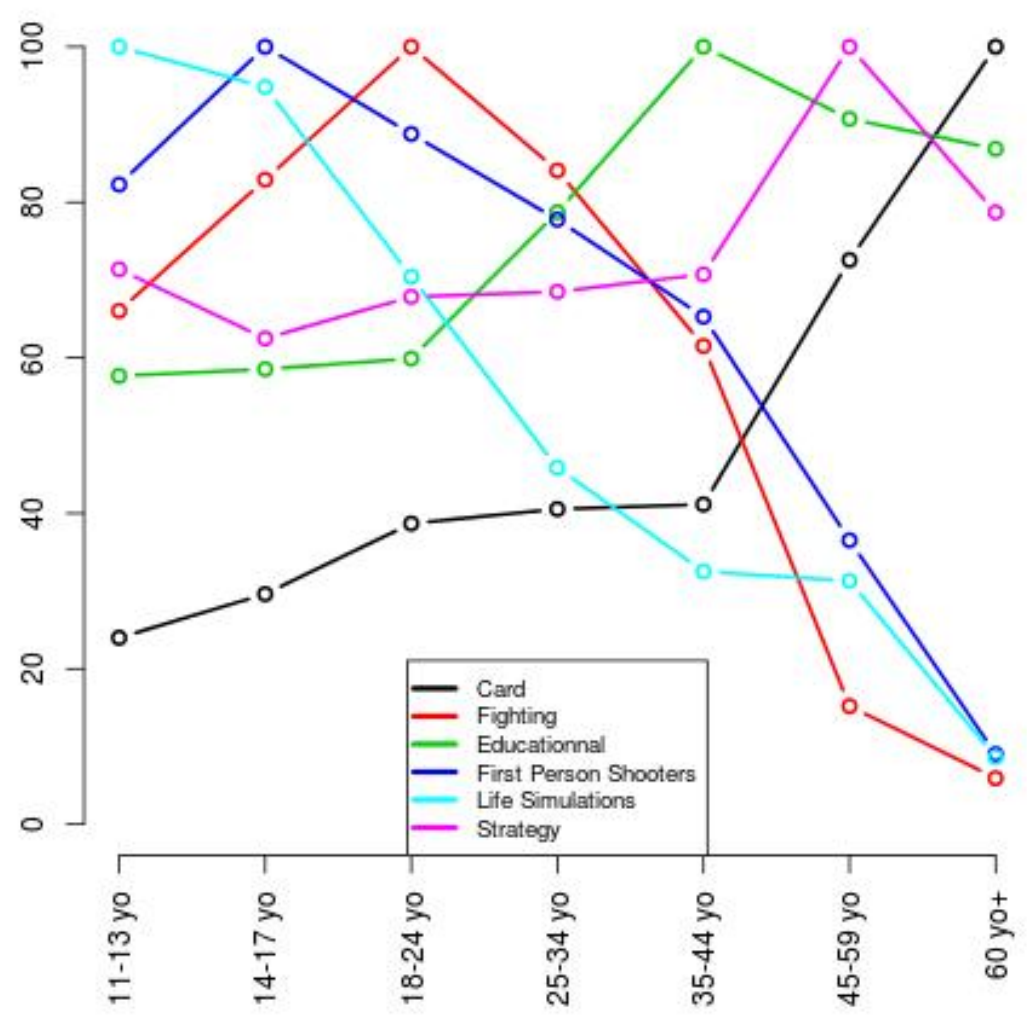

Image 5: Videogame genres practiced by different age groups.

Videogame genres appear also very distinctive between age groups. The younger the gamer the more different game genres he or she plays. So it may seem more difficult to distinguish the genre practices of older groups by using only raw data. The previous figure shows genre practices by age groups, weighting the practice by the average number of genres practiced in each group (base $100=$ maximum score within each age group). Older, younger, and middle-aged gamers seem clearly to focus on different game genres. Life simulation games (The Sims, animal breeding games, etc.) are almost exclusively popular among teenagers, and experience a sharp decline after 17 years of age. On the contrary, some genres actually increase with age, such as educational games, played mostly by 35 to 44 year old players with their children. Finally, card games (which include poker, but also traditional games, like belote or French tarot) are most popular among older players, aged 45 and over.

The different practices also mark the sociability the game requires. So when women play videogames, it is more often within the family circle, while men are 
likely to diversify the playmates and locations of the game. The distribution of videogames throughout society also promotes forms of socialization around the game, which is presented in contrast to the current stereotypes of isolation and withdrawal by videogame players. More than 4 out of 10 players play with friends and this even constitutes a majority among the most regular players.

\section{Exploring the impacts of the gaming environment}

The domestic space is the main venue for the practice of videogames: nearly 9 out of 10 adults play at home. But with the release of nomadic media games are accompanying players in their travels: at friends' homes (6 out of 10 players), but also in transport ( 3 out of 10 players). Generally, the more regular a practice is, the more it expands into different places, especially among younger players.

To explore the different gaming environments, a cluster analysis was performed on the places where people said they had played over the last 12 months: at home, at a neighbor's home, in the workplace, in transport, in public places, in a gaming center. The number of different places where they played was then scored. The six resulting clusters are presented in graphical form, along with the specific profile of each cluster according to six different places and its score to reveal overrepresentations and under-representations and associations. The figures represent the relation between the mean of the cluster and the mean of the entire population of players $(n=1697)$. A higher number indicates a concentration of people in this cluster who answered yes to the question, a figure close to 0 indicates that the cluster has no specificity compared to the general population for that question, and -1 indicates that no person in this cluster answered yes to this question. All game genres that people have played over the last 12 months are presented for each cluster using the same approach for ease of interpretation, but they have not been taken into account to achieve the clustering.

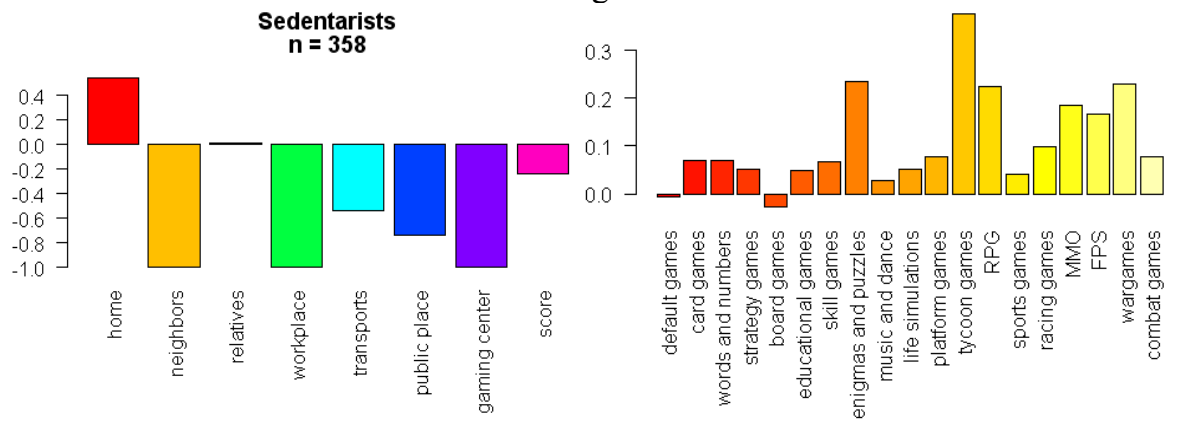

Image 6: Practices of the "sedentarists" (cluster 1).

The "sedentarists" (cluster 1,21\% of players) are people playing mostly at home, as much as the average with relatives, less than the average in transport or public places and nowhere else. In this cluster, people have played a few more game genres than the average. It groups people playing enigmas and puzzles, 
tycoon games, MMO, FPS and wargames. This cluster consists of two different populations, both those under 13 years of age and those over 35 years of age, with no gender difference, living with a partner and children or parents. The "sedentarists" are the youngest players and parents who play mainly at home, they tend to be executives, people with higher education and those undergoing training.
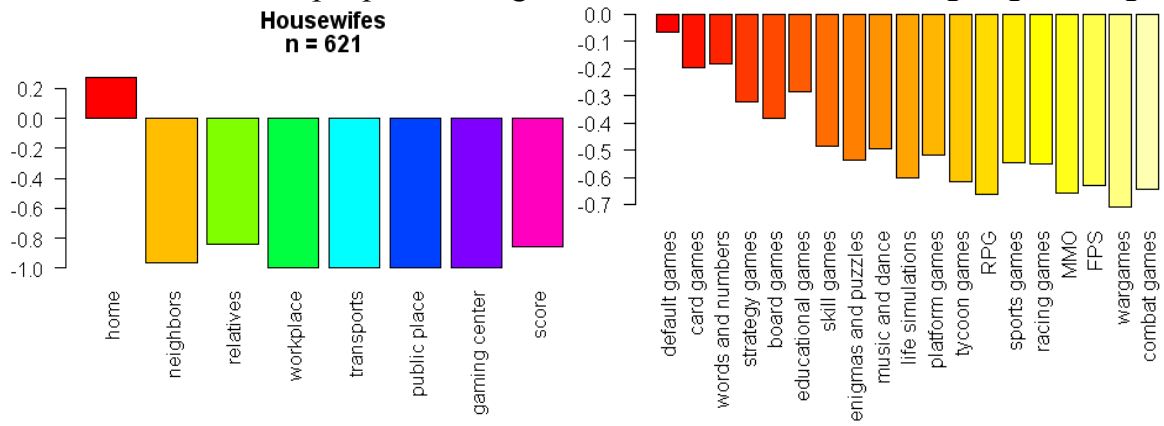

Image 7: Practices of the "housewives" (cluster 2).

The "housewives" (cluster 2, 36\% of players) are people playing only at home. In this cluster, people have played considerably fewer different kinds of games than other players. They exclusively played games installed by default on their machines, cards, word and number games, educational games and strategy games. Women over the age of 35 living with a partner and children are over-represented in this cluster. People with low academic or no other qualifications, farmers, pensioners and people with no occupation are also over-represented. The "housewives" tend to live in individual houses or subdivisions with three or more rooms and travel mostly using their own personal car. This is the group that has the least spectacular practices and is almost never considered in the literature.

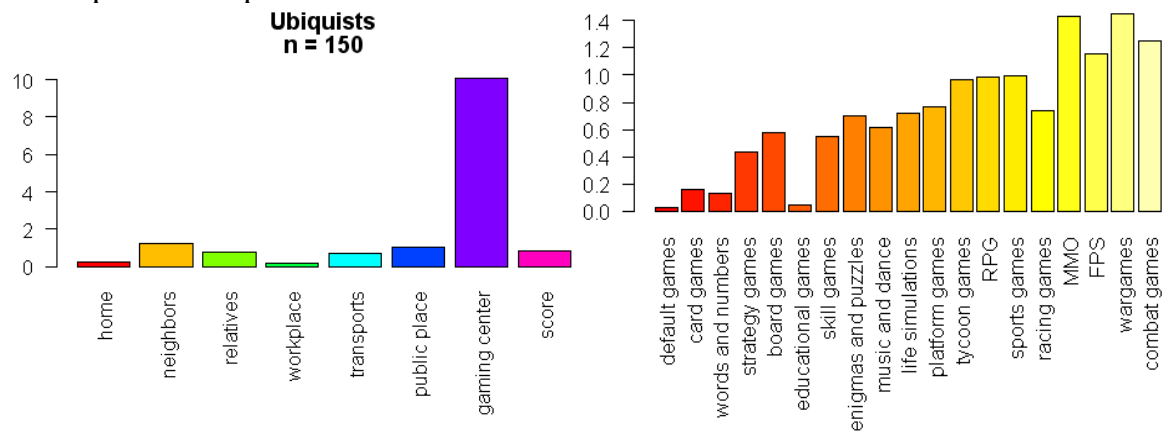

Image 8: Practices of the "ubiquists" (cluster 3).

The "ubiquists" (cluster 3, 9\% of players) play almost everywhere and are the only players who play in gaming centers. In this cluster, people have played a far greater variety of different games than other players, while these people have 
played fewer default games, cards, word and number games, and educational games. In this cluster, men younger than 18 years of age in training and middle class workers are over-represented. The "ubiquists" tend to live in urban areas and large metropolitan areas, often live with their parents, in flats of five rooms or more and moving on foot, by bike or skates.

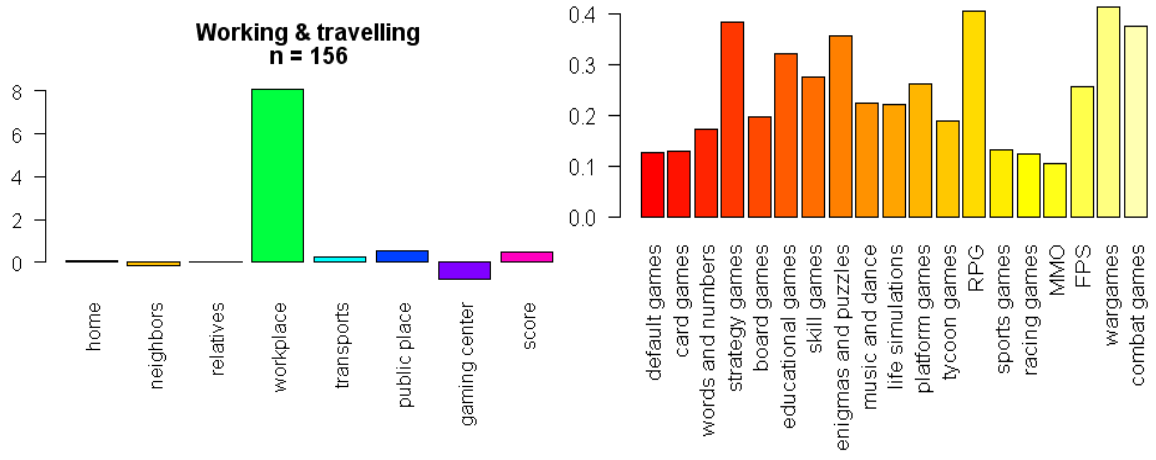

Image 9: Practices of the "working and travelling" (cluster 4).

The "working and travelling" (cluster $4,9 \%$ of players) are the only players who play at work. They also play slightly more in transport and public spaces, but not elsewhere. In this cluster, people have played a bit of all kinds of games, with a relative concentration of strategy games, puzzles and enigmas, RPG, FPS, combat games and wargames. In this cluster, youths 18 to 24 years of age, with no gender difference, and the working class, with low qualifications are over-represented. Far from the conventional wisdom, "working and travelling" do not represent management and executives. These are young professionals from the most popular classes, who tend to live on the periphery of major urban centers, often with their parents and using public transport over long distances (train and metro).

Neighborhood sociability $\mathrm{n}=\mathbf{2 0 1}$

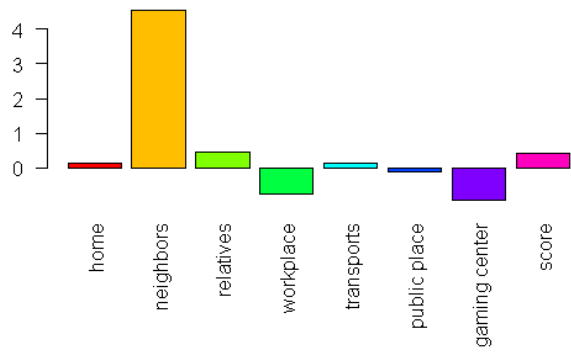

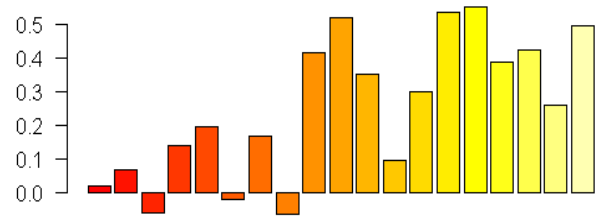

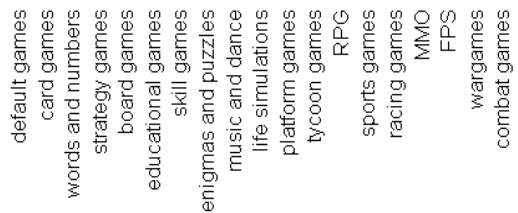

Image 10: Practices of the "neighborhood sociability" (cluster 5).

The "neighborhood sociability" (cluster $5,11 \%$ of players) are playing mainly at their neighbors' homes and to a certain degree at their relatives' place. In this 
cluster, people have played a slightly greater variety of games than other players. In particular it includes music and dance games, life simulation, platform, sports, racing and combat games. The "neighborhood sociability" cluster consists of men under 18 years of age, with an over-representation of persons undergoing training, blue collar workers, employees and intermediate occupations. They live mostly in rural areas or on the outskirts of small urban clusters, often with their parents in small dwellings or at boarding school and travel more on foot.

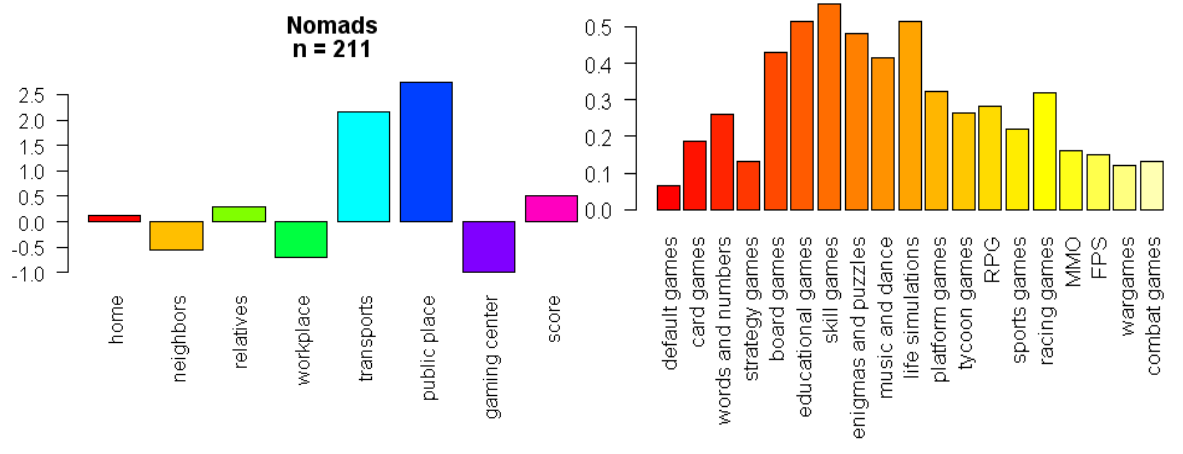

Image 11: Practices of the "nomads" (cluster 6).

The "nomads" (cluster 6,12\% of players) play both in transport and in public spaces, and to a lesser extent at their neighbors' or relatives' homes, yet in a greater variety of places than the average. In this cluster, people have played more different kinds of games than other players. In particular, it includes board games, educational, skill, enigmas and puzzles, music and dance games. The "nomads" are young adults under 35 years of age, with a slight over-representation of women. They tend to be executives and people with the highest levels of training, or people pursuing their studies. So, intellectuals, managers and executives tend to play in transport and in public spaces rather than at their place of work. This cluster includes the inhabitants of large urban centers, especially Parisians, people who tend to live with their parents or other family members, either in small apartments or in very large houses, and moving both by public transportation (bus, tram, metro) and green transportation (bicycle, roller-blades).

\section{Conclusion}

This is a work in progress that is presently being expanded, but also supplemented by qualitative interviews. It highlights the importance of not using $a$ priori definitions of players and videogames in order to collect the full spectrum of practices and audiences. These first results show the diversity of playing practices in space and time, and allow us qualifying the feminization of the public, challenging the image of executives playing at work, emphasizing that videogames seems to promote integration and decrease social withdrawal, and clarifying the differences between rural and urban practices when it comes to videogames. 
Moreover, the LUDESPACE study also shows that the practice of videogames does not compete with other cultural practices. In general, videogame players go to the cinema or the museum as much as their non-player counter parts, and at comparable ages they likewise share the same proportion of people practicing a sport or a musical instrument. Ultimately, videogames appear as a hobby among others within French cultural practices. ${ }^{15}$

\section{Notes}


${ }^{1}$ Samuel Rufat, Hovig Ter Minassian, Les jeux vidéo comme objet de recherche (Paris: Questions Théoriques, 2011).

${ }^{2}$ This work in progress takes place as part of the broader LUDESPACE research project, which is funded by the French National Research Agency (ANR 2011 JSH 001 01) and led by the laboratory CITERES (CNRS 7324). Its main aim is to describe in all their sociological and geographical diversity videogame players and videogame practices in France.

${ }^{3}$ Chloé Paberz, Rendre compte d'un ancrage local. L'apport original de l'ethnologie aux Game Studies, 2012.

${ }^{4}$ Pierre Bourdieu, Distinction. A Social Critique of the Judgment of Taste (Harvard University Press, 1984).

${ }^{5}$ Henri Lefebvre, The Production of Space (Oxford: Blackwell, 1991).

${ }^{6}$ Howard Becker, Outsiders. Studies in the sociology of deviance (New York: Free Press of Clencoe, 1963).

${ }^{7}$ T. L. Taylor, Play Between Worlds: Exploring Online Game Culture (The MIT Press, 2006).

${ }^{8}$ Pierre Bruno, Les Jeux vidéo (Paris: Syros, 1993).

${ }^{9}$ Laurent Trémel, Jeux de rôle, jeux vidéo, multimédia. Les faiseurs de monde (Paris: PUF, 2001).

${ }^{10}$ Vincent Berry, Les cadres de l'expérience virtuelle: Jouer, vivre et apprendre (PhD. Université Paris 13, 2009).

${ }^{11}$ Olivier Donnat, Les pratiques culturelles des Français à l'ère du numérique (Paris: La Découverte, 2009).

${ }^{12}$ Johan Huizinga, Homo ludens: a study of the play-element in culture (Boston: Beacon Press, 1955).

${ }^{13}$ Roger Caillois, Les Jeux et les hommes. Le masque et le vertige (Paris: Gallimard, 1958).

14 The importance of card games like Solitary, FreeCell, and Spider is confirmed when we look at the "most played games in the last 12 months". Solitary is the most mentioned game (it represents 2\% of the most played games mentioned), followed by Spider (1.7\%), FreeCell (1.6\%) and Poker (1.3\%) out of a total of 501 different references. 15 .

\section{Bibliography}

Inter-Disciplinary Press. Full Style Sheet, v. 9.0. Oxford: Inter-Disciplinary Press, 2013.

Becker, Howard. Outsiders. Studies in the sociology of deviance. New York: Free Press of Clencoe, 1963.

Berry, Vincent. Les cadres de l'expérience virtuelle: Jouer, vivre et apprendre. PhD. Université Paris 13, 2009.

Bourdieu, Pierre. Distinction. A Social Critique of the Judgment of Taste. Harvard University Press, 1984.

Bruno, Pierre. Les Jeux vidéo. Paris: Syros, 1993.

Caillois, Roger. Les Jeux et les hommes. Le masque et le vertige. Paris: Gallimard, 1958.

Corneliussen, Hilde G. and Rettberg, Jill Walker. Digital Culture, Play and Identity: A Reader. The MIT Press, 2008.

Debord, Guy. The Society of the Spectacle. Detroit: Black \& Red, 1967.

Donnat, Olivier. Les pratiques culturelles des Français à l'ère du numérique. Paris: La Découverte, 2009.

Huizinga, Johan. Homo ludens: a study of the play-element in culture. Boston: Beacon Press, 1955.

Lefebvre, Henri. The Production of Space. Oxford: Blackwell, 1991.

Paberz, Chloé. Rendre compte d'un ancrage local. L'apport original de l'ethnologie aux Game Studies, 2012.

Rufat, Samuel, Ter Minassian, Hovig. Les jeux vidéo comme objet de recherche. Paris: Questions Théoriques, 2011.

Taylor, T. L. Play Between Worlds: Exploring Online Game Culture. The MIT Press, 2006.

Trémel, Laurent. Jeux de rôle, jeux vidéo, multimédia. Les faiseurs de monde. Paris: PUF, 2001.

Samuel RUFAT: University of Cergy-Pontoise, Paris, France samuel.rufat@u-cergy.fr

Samuel COAVOUX: Ecole Normale Supérieure de Lyon, France, samuel.coavoux@ens-lyon.fr

Hovig TER MINASSIAN: University of Tours, France hovig.terminassian@univ-tours.fr 